\title{
Increase in Sharing of Stressful Situations by Medical Trainees through Drawing Comics
}

\author{
Theresa C. Maatman ${ }^{1}$ (D) Lana M. Minshew ${ }^{2,3} \mathbb{D} \cdot$ Michael T. Braun $^{2} \mathbb{D}$
}

Accepted: 20 October 2021 /Published online: 3 December 2021

(C) The Author(s), under exclusive licence to Springer Science+Business Media, LLC, part of Springer Nature 2021

\begin{abstract}
Introduction. Medical trainees fear disclosing psychological distress and rarely seek help. Social sharing of difficult experiences can reduce stress and burnout. Drawing comics is one way that has been used to help trainees express themselves. The authors explore reasons why some medical trainees chose to draw comics depicting stressful situations that they had never shared with anyone before. Methods. Trainees participated in a comic drawing session on stressors in medicine. Participants were asked if they had ever shared the drawn situation with anyone. Participants who had not previously shared were asked what prevented them and why they shared it now. The authors performed content analysis of the responses. Results. Of two hundred forty participants, forty-six (19.2\%) indicated sharing an experience for the first time. Analysis of the responses revealed dedicated time and space was essential to sharing, trainee insecurity was a barrier, and comics were perceived as a safe way to communicate. Discussion. Depicting a stressful situation may be beneficial for trainees who drew an experience they had never shared before. Providing trainees with the opportunity to externalize their experience and create a community for sharing tough experiences may be one way to reduce trainee stress and burnout.
\end{abstract}

Keywords Graphic medicine $\cdot$ Wellness $\cdot$ Provider stress $\cdot$ Medical education

Theresa C. Maatman

tmaatman@mcw.edu

Lana M. Minshew

lminshew@mcw.edu

Michael T. Braun

micbraun@mcw.edu

1 Department of Medicine, Medical College of Wisconsin, Milwaukee, WI, USA

2 Robert D. and Patricia E. Kern Institute for the Transformation of Medical Education, Medical College of Wisconsin, Milwaukee, WI, USA

3 Department of Clinical Sciences in the School of Pharmacy, Medical College of Wisconsin, Milwaukee, WI, USA 


\section{Introduction}

Medical training, whether in the classroom or in a clinical setting, is a challenging experience, and trainees may experience significant rates of depression as they go through their medical training (Dyrbye et al. 2015). Opportunities to reflect on these difficult experiences can aid trainees (see Artioli et al. 2021), but fear of stigmatization or punitive responses may prevent medical students from sharing their experiences with others (Winter et al. 2017). Similarly, reflective narratives from medical students demonstrate a need to suppress emotions they experience during their training (Gaufberg et al. 2010). Providing medical trainees (students and residents) with a safe space and opportunity to express their emotional responses to challenges that they encounter during their medical training may be beneficial. This study examines medical trainees who were asked to draw a comic depicting a stressful situation they encountered in their training. Of the two hundred forty participants who responded to the surveys, $19.1 \%$ reported depicting an event they had not shared with anyone before. Using open-coding qualitative analysis, we assess their reasons for sharing and consider comics as a potential means by which students can be encouraged to share difficult and stressful experiences.

\section{Benefits of sharing experiences with others}

The notion that talking to others about difficult situations is beneficial is commonly understood and represented in maxims such as "A burden shared is a burden halved." In an extensive review on the function of social sharing of emotions, Rimé (2009) demonstrates that social sharing of emotion aids in processing and understanding an emotional event (whether positive or negative), strengthening social ties, gaining assistance (e.g., comfort, advice), and creating a shared reality and understanding of a specific event or general situation. Relatedly, Ziegelstein (2018) argues that social components, including opportunities to share experiences with other medical trainees, must be part of trainee wellness programs because social support and social identification with others in the same position are key for reducing stress (Haslam et al. 2011).

Drawing comics is a way trainees may share difficult experiences, and the use of comics in medical training is called graphic medicine (Williams 2012). When trainees draw comics depicting their experiences, they often express difficult emotions (Maatman et al. 2020; George and Green 2015; Helmich et al. 2018; Julliard et al. 2002). This expression through comics has similar benefits to other kinds of social sharing and leads some students to share situations they had not shared with anyone before (Maatman et al. 2020). This research suggests students may be able to use drawings as a way of sharing negative emotions associated with their medical training.

Research on drawing comics as a way for medical trainees to share difficult emotions is in its early stages, and in this study, we investigate a foundational question about what and why trainees chose to share in their comics. Why do some medical trainees choose to share experiences they had never shared before when asked to draw a comic depicting a stressful situation? 


\section{Methods}

At a medical school in the Midwestern United States, medical trainees took part in one of seven workshop-style sessions on drawing comics during 2017 and 2018. Attendance for each session was not recorded, and approximately three hundred fifty-three enrolled trainees had the opportunity to attend a session. Sessions occurred as a single activity during the internal medicine intern retreat, the medical humanities elective, the second-year capstone course, the bioethics pathway and the third-year end of year intersession. Session length was variable and ranged from seventy-five to one hundred twenty minutes, with most sessions lasting approximately ninety minutes. The basic structure of each session consisted of education on comics (around ten minutes), time to draw a comic (thirty to sixty minutes), and opportunities to share their comics with other trainees (ten to twenty minutes). During these sessions, participants were asked to draw a comic expressing "something stressful in medicine." Comics were then shared with a group or a partner at the end of the session. In evaluating the effectiveness of the session, participants were surveyed with the questions: "Have you ever shared the experience you drew about with anyone?" If participants answered "yes," they were then asked two follow-up questions, "Why have you not shared it before?," and "Why did you share it now?" Participants wrote their answers on paper, and their responses were transferred to an Excel document for analysis.

Responses to the follow-up questions were reviewed independently by two coders who sorted the written responses based upon their content. The two coders then collectively discussed how the responses were sorted and talked through discrepancies. Four themes emerged from this process. This project was approved by the medical school's Institutional Review Board.

\section{Results}

A total of two hundred forty participants returned surveys, twelve first-year medical students (M1), thirty-two second-year students (M2), ninety-two third-year students (M3), thirty fourth- year students (M4), and seventy-four first-year internal medicine residents (PGY-1). Forty-six (19.2\%) participants reported that the comic they drew depicted a situation they had never shared with anyone (see Table 1). Thirty-three participants responded to at least one of the follow up questions. There were twenty-six responses for each follow up question, with nineteen participants responding to both questions, and fourteen answering only one of the two follow up questions. The content analysis revealed four distinct

Table 1 The number and percentage of medical trainees who shared a stressful situation for the first time using a comic

\begin{tabular}{lll}
\hline Training year & $\begin{array}{l}\text { Total Partici- } \\
\text { pated }\end{array}$ & $\begin{array}{l}\text { Number Sharing } \\
\text { for the First Time } \\
(\%)\end{array}$ \\
\hline Medical Student-First year & 12 & $3(25)$ \\
Medical Student-Second year & 32 & $7(21.9)$ \\
Medical Student-Third year & 92 & $18(19.6)$ \\
Medical Student-Fourth year & 30 & $6(20)$ \\
Internal Medicine Intern & 74 & $12(16.2)$ \\
Total & 240 & $46(19.2)$ \\
\hline
\end{tabular}


themes: time and space, insecurity, benefits of reflective cartooning, and reflections on task.

\section{Theme 1. Dedicated time and space for sharing}

Some participants stated they shared their stressful experiences for the first time because they were given the time and space to do so. Trainees noted they had not previously shared the experience because they had "no perceived time to do so," "no time" or "no opportunity" prior to the comic session. Participants also shared that they did not have someone they generally talked to about stressful situations. For instance, one trainee stated, "I don't talk to that many people," and another noted, "I generally keep stresses to myself."

Regarding why participants selected this moment to share the stressful event, trainees noted they "had opportunity," "there was an avenue for sharing," had a "safe space to share" and that "everyone else shared." Further, one participant acknowledged that the comic session allowed them to explore what was "on my mind" and another participant stated, "Not exactly sure. It's just what came out."

\section{Theme 2. Insecurity}

The theme of insecurity stems from either the participants' vulnerability experienced from sharing or their embarrassment surrounding the incident. Vulnerability and weakness were specifically noted in several of the responses as reasons why participants had not shared their experiences before. Trainees reported their stressful experience was "Personal. Makes me feel vulnerable," and that they were "scared they [others] will judge [me]" if they shared their experience. One participant stated, "If they [the stressful situations] are of my own making and highlight a personal weakness," then they were reluctant to share with others. One trainee aptly stated, "it is not easy to share with everyone."

Feelings of insecurity also encompassed trainees' feelings of weakness. Several comments focused on feeling weak due to the participant divulging behavior that is perceived to be less than ideal. One participant pointed out they never told anyone about their experience because "I didn't like how I reacted and handled myself." Another trainee simply stated, "You can't talk about being insecure in medical school."

\section{Theme 3: Benefit of reflective cartooning}

Although trainees were not prompted to discuss the potential benefits of drawing cartoons depicting stressful situations, several acknowledged that the activity was helpful in allowing them to explore their experience and share with their colleagues. One participant shared that the comic allowed her to tell her story, and she "didn't have to tell anyone how they handled it." Another trainee found using comics prompted him to tell a story that he "doesn't need to explain." Further, participants noted they engaged in sharing because it might allow them to connect with others who had "experience[d] a similar situation." Finally, one trainee profoundly stated, "In sharing we find solace and healing."

\section{Theme 4: Reflections on task}

Some participants noted their reactions to the task (creating a comic) itself, not their reactions to what they shared. For example, some trainees commented on the challenge and 
limitations of their artistic skills, saying "[I] don't like my drawing ability" and "I don't really draw that much." Additionally, there were several responses that suggested the trainees were only sharing now because "it was part of the assignment" and "because everyone else shared."

\section{Discussion}

Medical training can be isolating, and trainees often experience long hours, busy schedules, and remote work due to health and safety protocols associated with the COVID-19 pandemic. These factors, combined with the stigma of expressing and sharing negative experiences, may leave some trainees without opportunities to share stressful experiences from their medical education. Finding ways to help trainees share experiences may be beneficial, and this study used a comic drawing task to encourage expression of these experiences. Because there is limited research exploring the use of drawing comics in this setting, this observational study explored the responses of medical trainees who reported drawing a comic about a stressful situation they previously had not shared with anyone. Their responses to two follow up questions were qualitatively coded to identify why the trainees chose to share their experience. Four themes, dedicated time and space for sharing, insecurity, benefit of reflective cartooning and reflections on task emerged from the data.

Time and Space: In the current study, many trainees identified that being given time and space to share is what prompted them to be open and talk about a stressful incident. Providing dedicated time and a safe space can allow for sharing which is important for trainees who may not have the ability to share in other ways (Ziegelstein 2018). Further, social connection, specifically establishing meaningful connections with one's peers has the potential to promote well-being, reduce burnout (Ziegelstein 2018) and foster resilience (Beresin et al. 2016). Providing time for medical trainees to reflect (e.g., draw a comic) on a stressful experience and then share with peers can support trainee well-being.

Insecurity: Trainee responses expressed feelings of vulnerability and weakness from sharing stressful experiences with others. In the past, physicians were notorious for their reluctance to admit weakness and engage in discussions highlighting their struggles that would make them appear less than their peers (Bersein et al. 2016). The trainee response of "You can't talk about being insecure in medical school" signifies that, despite promoting well-being and engaging in mental health initiatives, there is still a problem regarding the acceptability of sharing and expressing feelings in medical education. Molloy and Bearman (2019) argue that hiding vulnerabilities can interfere with learning and quality of practice. In this study, nearly $20 \%$ of participants had never shared or discussed the stressful experience with anyone, which may lead to missed opportunities for learning, reflection and potential growth as a practitioner.

Benefits: Stressful or traumatic experiences can result in reduced self-confidence, reduced feelings of self-efficacy and lower self-esteem (Rimé 2009). Studies have shown that socially sharing an emotional experience leads to emotional recovery (Zech and Rimé 2005; Rimé 2009; Rimé et al. 2020). By having trainees graphically depict a stressful situation and then socially share the comic, trainees may have been aided in their recovery from the experience. Emotional experiences serve as a catalyst for interpersonal relationships (Rimé et al. 2020); thus having a structured activity creates the opportunity to increase social supports among trainees, which can be critical for vulnerable individuals (Ziegelstein 2018). Further, structured activities that engage trainees in sharing and discussing 
stressful situations may help to change the norms and culture of sharing vulnerabilities in medical education.

Reflecting on the Task: As with most educational activities, there was a range of buy-in from the participants, and some participants' comments reflected their views on the task itself instead of anything they may have learned or experienced because of their participation. Even among trainees who depicted an event they had not shared before, they did not describe any benefit they experienced from doing so. While comics may aid some participants in sharing, it is unlikely to have that effect on all participants.

\section{Limitations}

This study has many limitations. First, the sample size was small, with only thirty-three ( $20 \%)$ trainees responding to the follow-up questions acknowledging they shared something they had not previously shared before. Future studies should increase the sample size to support generalization of the findings. We cannot conclude that the participants of this study represent medical trainees overall, and this was not the intention of this paper. Additionally, many of the responses to the open-ended questions were short and did not include many details. This study did not compare comics with any other method by which participants could be prompted to share stressful situations, such as writing an essay. As such, we cannot make any determination about the effectiveness of comics in comparison to other means of sharing and reflection. Lastly, the use of paper surveys could be a limiting factor; participants may respond more readily or in greater detail to a digital survey.

Future studies should include a more extensive survey instrument to capture a greater breadth and depth of the trainee experience. Additionally, follow-up interviews could be implemented to gain a deeper understanding of the emotions and motivation regarding trainee sharing of an experience for the first time.

Acknowledgements We acknowledge the assistance of individuals Kristina Kaljo, Keith Nakamura, and the Kern Institute Collaboration for Scholarship (KICS), funded by a gift from the Kern Family Foundation.

Authors Contributions The lead author (TM) conducted data collection, data analysis, wrote the first draft of the manuscript, and approved the final draft of the manuscript. The other authors (LM \& MB) critically reviewed and edited the manuscript and approved the final draft.

\section{References}

Artioli, Giovanna, Lara Deiana, Francesco De Vincenzo, Margherita Raucci, Giovanna Amaducci, Maria Chiara Bassi, Silvia Di Leo, Mark Hayter, and Luca Ghirotto. 2021. "Health Professionals and Students' Experiences of Reflective Writing in Learning: A Qualitative Meta-synthesis." BMC Medical Education 21. https://doi.org/10.1186/s12909-021-02831-4.

Beresin, Eugene V., Tracey A. Milligan, Richard Balon, John H. Coverdale, Alan K. Louis, and Laura Weiss Roberts. 2016. "Physician Wellbeing: A Critical Deficiency in Resilience Education and Training." Academic Psychiatry 40:9-12. https://doi.org/10.1007/s40596-015-0475-x.

Dyrbye, Liselotte N., Anne Eacker, Steven J Durning, Chantal Brazeau, Christine Moutier, F. Stanford Massie, Daniel Satele, Jeff A. Sloan, and Tait D Shanafelt. 2015. "The Impact of Stigma and Personal Experiences on the Help-seeking Behaviors of Medical Students with Burnout." Academic Medicine 90 (7): 961-969. https://doi.org/10.1097/ACM.0000000000000655.

Gaufberg, Elizabeth H., Maren Batalden, Rebecca Sands, and Sigall K. Bell. 2010. "The Hidden Curriculum: What can we learn from third-year medical student narrative reflections?" Academic Medicine 85 (11): 1709-1716. https://doi.org/10.1097/ACM.0b013e3181f57899. 
George Daniel R. and Michael J. Green. 2015. "Lessons Learned from Comics Produced by Medical Students: Art of Darkness." JAMA 314 (22): 2345-2346. https://doi.org/10.1001/jama.2015.13652.

Haslam, S. Alexander, Anne O’Brien, Jolanda Jetten, Karine Vormedal, and Sally Penna. 2011. “Taking the Strain: Social Identity, Social Support, and the Experience of Stress.” British Journal of Social Psychology 44 (3): 355-370. https://doi.org/10.1348/014466605X37468.

Helmich, Esther, Laura Diachun, Radha Joseph, Kori LaDonna, Nelleke Noeverman-Poel, Lorelei Lingard, and Sayra Cristancho. 2018. “'Oh my God, I can't handle this!': Trainees' Emotional Responses to Complex Situations." Medical Education 52 (2): 206-215. https://doi.org/10.1111/medu.13472.

Julliard, Kell, Nancy Intilli, Jennifer Ryan, Sarah Vollmann, and Mahalakshmi Seshadri. 2002. "Stress in Family Practice Residents: An Exploratory Study using Art.” Art Therapy 19 (1): 4-11. https://doi.org/ 10.1080/07421656.2002.10129727.

Maatman, Theresa C., Branden Vugrnick, Colleen Manak, Marika Wrzosek, Craigan Ushar, Joni Williams, and Kathlyn E. Fletcher. 2020. "Emotional Content of Comics Drawn by Medical Students and Residents." Academic Psychiatry 44: 572-576. https://doi.org/10.1007/s40596-020-01261-6.

Molloy, Elizabeth, and Margaret Bearman. 2019. "Embracing the Tension between Vulnerability and Credibility: 'Intellectual candour' in Health Professions Education.” Medical Education 53 (1): 32-41. https://doi.org/10.1111/medu.13649.

Monk, J. 2018. "Go Home, Med Student: Comics as Visual Media for Students' Traumatic Medical Education Experiences." AMA Journal of Ethics 20 (1): 144-147. https://doi.org/10.1001/journalofethics. 2018.20.2.ecas2-1802.

Rimé, Bernard. 2009. "Emotion Elicits the Social Sharing of Emotion: Theory and Empirical Review." Emotion Review 1 (1): 60-85. https://doi.org/10.1177/1754073908097189.

Rimé, Bernard, Pierre Bouchat, Louise Paquot, and Laura Giglio. 2020. "Intrapersonal, Interpersonal, and Social Outcomes of the Social Sharing of Emotion.” Current Opinion in Psychology 31:127-134. https://doi.org/10.1017/j.copsyc.2019.08.024.

Whiting, Jack. 2020. "Comics as Reflection: In Opposition to Formulaic Recipes for Reflective Processes." The Permanente Journal 24:19.134. https://doi.org/10.7812/TPP/19.134.

Williams, Ian C. M. 2012. "Graphic Medicine: Comics as Medical Narrative." Medical Humanities 38 (1): 21-27. https://doi.org/10.1136/medhum-2011-010093.

Winter, Rachel I., Rakesh Patel, and Robert I. Norman. 2017. "A Qualitative Exploration of the Helpseeking Behaviors of Students who Experience Psychological Distress around Assessment at Medical School." Academic Psychiatry 41 (4): 477-485. https://doi.org/10.1007/s40596-017-0701-9.

Zech, Emmanuelle and Bernard Rimé. 2005. "Is talking about an emotional experience helpful? Effects on Emotional Recovery and Perceived Benefits." Clinical Psychology \& Psychotherapy 12:270-287. https://doi.org/10.1002/cpp.460.

Ziegelstein, Roy C. 2018. "Creating Structured Opportunities for Social Engagement to Promote Well-being and Avoid Burnout in Medical Students and Residents. Academic Medicine 93 (4): 537-539. https:// doi.org/10.1097/ACM.0000000000002117.

Publisher's Note Springer Nature remains neutral with regard to jurisdictional claims in published maps and institutional affiliations. 